UDC 316.472 .43

LBC 60.561 .5

\title{
SMART THINGS OF THE CENTURY: NEW TECHNOLOGIES IN CHILDREN-PARENT RELATIONS ${ }^{1}$
}

\author{
Elena G. Laktyukhina \\ Volgograd State University, Volgograd, Russian Federation
}

\begin{abstract}
The article is devoted to the problem of interaction between parents and children in the conditions of using digital gadgets. The topic is updated by the fact that in the past few years, new media technologies have been profiled for a specific user, gadgets and devices for user groups of parents are widely introduced. These devices monitor the child's physiological indicators, his movements and inform the parents about them. Using the language of research in science and technology, we can say that these devices are "embodied ideology," that is, technologies allow the development of the interests of users, their attitudes, motives, and practices along one channel, guide and prescribe actions to their users. The article presents the results of the analysis of press releases of these gadgets that represent the ethics of parent-child relationships and the practice of caring for a child in the new digital everyday life. In addition, expert reports and feedback from parents-users were analyzed. One of the main results of the work is the conclusion that children's gadgets reinforce the idea of the need for a special relationship to all children, primarily through constant monitoring of them. In addition, the spread of digital infrastructure in the field of childcare occurred in the context of the medicalization of the discourse about childhood. It has shaped modern children's monitors functionally similar to medical devices. This situation contributes to the formation of a medically vigilant parent, his new competence is a deep knowledge of the child's physiology. Negative consequences for children of this form of control can be the formation of the habit of being under observation, difficulties in the development of urban space, lack of independence in actions and decision-making.

Key words: smart things, parenthood, childhood, new media, baby monitor, medicalization.
\end{abstract}

УДК 316.472 .43

ББК 60.561 .5

\section{УМНЫЕ ВЕЩИ ВЕКА: НОВЫЕ ТЕХНОЛОГИИ В ДЕТСКО-РОДИТЕЛЬСКИХ ОТНОШЕНИЯХ ${ }^{1}$}

\author{
Елена Геннадьевна Лактюхина \\ Волгоградский государственный университет, г. Волгоград, Российская Федерация
}

\begin{abstract}
Аннотация. Статья посвящена проблеме взаимодействия родителей и детей в условиях использования цифровых гаджетов. Тема актуализируется тем, что в последние несколько лет технологии новых медиа профилируются под конкретного пользователя, широко внедряются гаджеты и девайсы для пользовательских групп родителей. Эти девайсы осуществляют мониторинг физиологических показателей ребенка, его перемещений и информируют родителей о них. Пользуясь языком исследований науки и технологии, мы можем сказать, что эти устройства являются «воплощенной идеологией», то есть технологии допускают развитие интересов пользователей, их установок, мотивов и практик по одному какому-либо руслу, направляют и П предписывают действия своему пользователю. В статье представлены результаты анализа пресс-релизов 국 этих гаджетов, которые репрезентируют этику детско-родительских отношений и практики ухода за ребенком в новой дигитальной повседневности. Одним из основных результатов работы является вывод о том, что детские гаджеты укрепляют идею необходимости особого отношения ко всем детям, прежде всего с помощью постоянного наблюдения за ними. Кроме того, расширение цифровой инфраструктуры на область ухода за детьми произошло в условиях медикализации дискурса о детстве. Это сформировало современные детские мониторы функционально похожими на медицинские приборы, что способствует формированию медицински бдительного родителя, новой компетенцией которого становится глубокое знание физиологии
\end{abstract}


ребенка. Негативными последствиями для детей такой формы контроля может стать формирование привычки быть под наблюдением, трудности в освоении городского пространства, несамостоятельность в действиях и принятии решений.

Ключевые слова: умные вещи, родительство, детство, новые медиа, детский монитор, медикализация.

\section{Введение}

В последнее десятилетие существенно меняются объективные условия рождения, воспитания, социализации детей и их всестороннего развития. Во-первых, средний возраст родителей при рождении детей заметно повышается (особенно в крупных городах), матери старших возрастов все чаще демонстрируют в воспитании ребенка модели ответственного родительства и «профессионального материнства», которые характеризуются высокой эмоциональной вовлеченностью в жизнь ребенка, сосредоточенностью на его интересах, постоянным участием в развитии ребенка. Во-вторых, снижается доля участия старших родственников в воспитании и уходе за ребенком, родительство индивидуализируется, постепенно нивелируются границы между социальными нормами материнства и отцовства. В-третьих, психолого-педагогический дискурс, доминировавший на протяжении всего XX в. в сфере регламентации воспитания ребенка, сменяет индустрия детства, контролируемая рынком и предлагающая широкий спектр товаров и услуг для детей и их родителей. Появляются идеи «ответственного родительства», «интенсивного родительства», опережающего развития, приверженности к определенному способу ухода за ребенком или, наоборот, отказа от устоявшихся практик изза недоверия к нормам и требованиям традиционных моделей родительства (отказ от прививок или использования ходунков) [Майофис, Кукулин 2010; Шпаковская 2013; Hochschild 1995].

Ни одна из моделей родительства, существующих сегодня, не является доминирующей или однозначно поддерживаемой общественным дискурсом. Такая ситуация является отражением характерных для современного общества глобальных общемировых процессов, происходящих, в том числе, и под влиянием сложившейся постиндустриальной медиакультуры. Сегодня молодые родители не могут в полной мере ис- пользовать опыт собственных родителей и старших родственников, так как те воспитывали своих детей в принципиально иных условиях. Новые медиа предлагают возможность, скорее, обращаться к опыту «незнакомца» в сетевых сообществах и открывают доступ практически к специализированной информации. Новое поколение молодых родителей, сформировавшееся за это время, ориентировано на обращение к экспертному знанию. Они демонстрируют высокую осведомленность в вопросах психофизиологии ребенка, регулярно прибегают к помощи специализированных интернет-ресурсов, используют мобильные приложения, информирующие о развитии ребенка, предлагающие формы досуга для него и т. д. [Свешникова 2010; Palmer 2006].

Массовое использование цифровых устройств для детей начинается с 2010-х годов. На цифровом рынке появляются два самых популярных в настоящее время гаджета для детей: цифровая видеоняня и умные часы. Видеоняня является цифровой версией устройства, появившегося еще в 1980-е, но теперь, помимо простой передачи видеоизображения ребенка, оно обладает функциями ночной съемки, трансляции колыбельных ребенку, измерения температуры в комнате и т. д. Кроме того, сигнал передается прямо на смартфон родителей. Умные часы (smart watch) - гаджет для детей постарше. Технологически они являются продолжением систем мониторинга передвижений с помощью GPS, которые используются и для отслеживания грузов, транспорта и сотрудников, чья работа связана с поездками. Однако с точки зрения практик использования умные часы поддерживают новый режим взаимодействия между родителями и детьми, заданный изобретением радионяни. Целью данной статьи является анализ этих режимов взаимодействия, задаваемых умными технологическими устройствами, которые получили широчайшее распространение в последние несколько лет. 


\section{Радионяня: наблюдение и память}

Главной (и единственной) функцией первой радионяни была передача звука: взрослый получает возможность услышать плач ребенка из другой комнаты или сада, прийти и успокоить его. Первые рекламные проспекты сообщали, что радионяня дает возможность определять по звукам состояние не только ребенка, но и пожилого или больного человека. Обратимся к современным смарт-мониторам. Из числа наиболее популярных брендов детских мониторов были отобраны шесть моделей, представленных на российском цифровом рынке (Angelcare, Beurer, IBaby, Motorola, Monbaby, Philips), и столько же из числа популярных в странах Западной Европы и США (Vetch, Summer Infant, Nanit, IBaby, Philips, Babysense). Для анализа взяты прессрелизы выбранных мониторов и их описания на официальных сайтах производителей.

Эти тексты описывают не только диапазон функций, но также этику детско-родительских отношений и практики ухода за ребенком в новой дигитальной повседневности. Именно этому и был посвящен проведенный контент-анализ, направленный на поиск прагматических структур текста. Была выделена центральная категория «уход за ребенком / забота о ребенке» и связанные с ней: «ребенок», «родитель», «наблюдение». В русскоязычных текстах ребенок описывается как спящий, неугомонный, капризничающий, кричащий, плачущий. В описании «уход за ребенком» доминирует ориентация на решение проблем ребенка на расстоянии («успокоить голосом, не подходя к ребенку», решать проблемы ребенка, «не отвлекаясь от повседневных дел», включить колыбельную ребенку из «любой точки планеты»). С категорией «уход за ребенком» связаны категории контроля. Контроль описывается через наблюдение («увидеть, чем ребенок занимается») и слежение, они характеризуются как «постоянные», «комфортные для родителя», «пристальные». В рекламных текстах гаджет представлен как помогающий родителю (и нужный прежде всего ему) выполнять свои родительские роли с меньшими временными и эмоциональными затратами, а родитель - как «занятый другими делами», стремящийся как можно мень- ше подходить к ребенку. При этом родителю атрибутируется желание не пропустить памятные моменты, связанные с ребенком, зафиксировать их на видео и делиться ими с родственниками и друзьями. Идея необходимости этого гаджета самому ребенку обнаруживается только в одном из текстов: радионяня поможет ребенку заснуть, так как снабжена колыбельными мелодиями. Категория безопасности фигурирует в связке с комфортностью и экологичностью самого гаджета, его безвредностью для ребенка. Тема безопасности ребенка, присутствовавшая в первых рекламных текстах радионяни, сохраняется в описаниях тех моделей гаджетов, которые сочетают в себе функции мониторов дыхания. Их описания поддерживают медицинский дискурс заботы о младенце, где доминирует предотвращение синдрома внезапной детской смерти - CВДС (SIDS), и имеют ссылки на медицинские исследования.

В англоязычных текстах есть некоторые отличия в представлении выделенных категорий. Уход за ребенком отображен в большей степени через заботу о его сне, покое и развитии, которые обеспечиваются белым шумом, ночником, колыбельными и детскими песнями. Категория «покой» связана и с родителями («душевное спокойствие»«peace of mind», «спокойный сон»). Родителю атрибутируется желание наблюдать «каждую улыбку» ребенка. Ребенок описывается как «играющий»), «спящий»), «нуждающийся в утешении». Дискурс англоязычных пресс-релизов менее дисциплинарен по отношению к ребенку, фокус внимания в них направлен на интимность отношений родителя и ребенка. Наблюдение и слежение через категорию «связи с ребенком на расстоянии» соединяются с категориями помощи / утешения на расстоянии или сообщения ему о том, что родитель уже идет к нему («comfort your baby with the sound of your own voice by using the two-way talk back system»).

\section{Умные часы: между контролем и заботой}

С достижением ребенком возраста трех лет видеоняню сменяет другое устройство умные часы. Это второй по популярности гаджет, покупаемый родителями. Вот стандарт- 
ный набор функций этих часов: GPS-трекер (наблюдение перемещений пользователя часов на виртуальной карте приложения-компаньона, которое загружается на смартфон родителей или опекунов, возможность отмечать разрешенные зоны для посещения ребенком, при выходе ребенка из них родитель получает уведомление), телефонный звонок (телефонные номера может загружать в гаджет только взрослый), кнопка SOS (передача координат местонахождения пользователя и голосового сообщения на телефонные номера родителей), прослушка (возможность установить одноканальное аудиосоединение с часами и услышать все, что происходит вокруг пользователя часов без его ведома и согласия), одни модели снабжены дополнительными функциями фото- и видеосъемки, калькулятором, шагомером и играми, на других отсутствуют функции прослушки или трекера.

Обратимся к текстам, описывающим умные часы. Анализу были подвергнуты две группы текстов (пресс-релизы с официальных сайтов производителей) популярных моделей умных часов в русскоязычном [Caref, DokiWatch, Kidizoom, Smart Baby Watch (две разных модели), Кнопка жизни] и англоязычном пространстве (DokiWatch, Filip, Kidizoom, Kidsport, Wizard). Центральная категория «уход за ребенком / забота о ребенке», как и в текстах о видеоняне, раскрывается через категории наблюдения, контроля, постоянной связи с ребенком, а также слежения. В русскоязычных текстах доминируют категории «контроль» и «слежение / слежка». Контроль выражается в знании обо всех перемешениях ребенка, об «отклонениях от маршрута», «нарушении границ» разрешенной территории, вся мобильность ребенка описывается как дисциплинарный проступок. Кроме того, контролю подлежит слишком низкая мобильность ребенка в пределах заданной зоны, она определяется шагомером часов и соотносится с потребленными ребенком калориями. Категории «прослушка», «подслушивание», «слежение / слежка» относятся к деятельности ребенка, которая представляется как нежелательная или вредная, а также к окружающим его взрослым (предлагается «подслушать», о чем говорит няня с ребенком в отсутствие родителя, контекст предполагает, что говорит она с ним о чем-то нежелательном). Ребенок в текстах описывается как хвастливый, скрытный, нарушающий правила, играющий, увлекающийся. Родителю имплицирована роль надзирателя ребенка. Тема игровых приложений в большей степени связана с развитием навыков ребенка (например, математических), чем с его развлечением. Сам гаджет описывается как экологичный, безопасный, обеспечивающий безопасность.

В текстах, ориентированных на европейский и американский рынок, темы наблюдения и контроля раскрываются через категории «свободы ребенка», «самостоятельности» («give your kids independence»), «постоянной связи с семьей» («families need to stay connected»). Тема наблюдения связывается не с обнаружением проступка ребенка, а с информацией о том, что у ребенка все хорошо и волнение родителя напрасно. Текст одной из изучаемых моделей часов сообщает, что гаджет предупреждает о выходе из разрешенной зоны не только родителя, но и ребенка. Это говорит о том, что поведение ребенка квалифицируется не как проступок, а как результат увлеченности игрой. Тема наблюдения раскрывается через категории постоянной связи, получения знания о месте, сопровождения. «Прослушка» ребенка описывается как альтернатива навязчивым звонкам, связана с темой уважения личного пространства («Use the app to call your kids without being disruptive»). С категорией «родитель» связаны категории «волнение», «стресс», «беспокойство за ребенка». Ребенок описывается как играющий, творческий, веселый, развивающийся, рассеянный. Совокупно описание темы игры и творческого развития ребенка с помощью гаджета значительно превышает описание этой темы в аналогичных русскоязычных текстах.

Вопрос агентности детей сформулирован в рамках новой социологии детства в 1990-х годах. Он связан с критикой психолого-педагогических идей универсальной природы ребенка и обязательности «нормативного» детства. В новой концепции дети понимаются как эксперты в своей жизни, они способны к участию в решении вопросов, касающихся их повседневной жизни, и имеют право выражать свои взгляды [Donoso et al. 2016; Valentine, Mckendrick 1997; Qvortrup 1991; Barker 2003]. 
До последнего времени асимметрия в отношениях между детьми и взрослыми регламентировалась обязанностями последних выполнять социализационные функции. Этот порядок разрушается в условиях технокультуры, когда опыт слишком быстро устаревает и каждый вне зависимости от возраста занимает позицию ученика [Bijker, Hughes 1993]. Использование детских мониторов и других следящих гаджетов создает ситуацию столкновения двух режимов - права детей на автономию и обязанности родителей нести ответственность за безопасность своих детей. Современные детские мониторы и следящие устройства как технология находятся на этапе становления, она довольно пластична, ее функциональность меняется. К тому же эти гаджеты имеют слабую социальную укорененность. Однако очевидным является то, что идеология детства и родительства меняется и новые паттерны детско-родительских отношений будут закрепляться в технологических посредниках.

\section{Заключение}

Вслед за Дэвидом Роузом, который в своей книге «Будущее вещей: Как сказка и фантастика становятся реальностью» [Rose 2014] проводит параллель между волшебными вещами в сказках и Интернетом вещей, хочется сравнить детские мониторы, позволяющие фиксировать состояние ребенка и его перемещения, с волшебным зеркальцем из сказки братьев Гримм, которое по запросу отвечает, где находится интересующий героя субъект, дает возможность «подсмотреть» за ним. Однако, в отличие от волшебных предметов, смартконтроль не позволяет узнать настроение, состояние дел ребенка, то есть ничего, кроме его местоположения или физиологических характеристик. Родители не способны повлиять на перемещения ребенка или его состояние с помощью технологического устройства, они могут только фиксировать его. Растущая популярность умных вещей все больше закрепляет за родителями ответственность за детей, делая ее персональной [Blinkert 2004]. Это снимает обязанность с каждого прохожего, если речь идет о детях на улице, контролировать общественный порядок в зоне собственной досягаемости [Fotel, Thomsen 2004; Goodchild
2007]. В новой цифровой реальности родители обречены на балансирование между необходимостью интерпретации новой информации о ребенке и моральностью ее разглашения, между погруженностью в мир ребенка благодаря постоянному цифровому присутствию и собственной автономией, между контролем и заботой.

\section{ПРИМЕЧАНИЕ}

${ }^{1}$ Исследование выполнено при финансовой поддержке РФФИ в рамках научного проекта № 18011-00692 «Родительство в эпоху “умных вещей”: социологический анализ».

The reported study was funded by RFBR according to the research project no. 18-011-00692 "Parenthood in the era of 'smart things': a sociological analysis".

\section{СПИСОК ЛИТЕРАТУРЫ}

Майофис, Кукулин 2010 - Майофис М.Л., Кукулин И.В. Новое родительство и его политические аспекты // Pro et Contra. 2010. T. 14, № 1-2. C. 6-19.

Свешникова 2010 - Свешникова О. Российские родители: новое в поведении и мировосприятии // Pro et Contra. 2010. T. 14, № 1-2. C. 61-77.

Шпаковская 2013 - Шпаковская Л.Л. Дискурсивные практики родительства: политические вызовы и актуальные проблемы // Вестник Томского государственного университета Философия. Социология. Политология. 2013. № 1 (21). C. 236-248.

Barker 2003 - Barker J. Passengers or Political Actors? Children's Participation in Transport Policy and the Micro Political Geographies of the Family // Space and Polity. 2003. Vol. 7 (2). P. 135-151.

Bijker, Hughes, Pinch 1993 - Bijker W.E., Hughes T.P., Pinch T.J. The Social Construction of Technological Systems. New directions in the Sociology and History of Technology. L.: The MIT Press Cambridge, 1993.

Blinkert 2004 - Blinkert B. Quality of the City for Children: Chaos and Order // Children, Youth and Environments. 2004. Vol. 14 (2). P. 99-112.

Donoso et al. 2016 - Donoso V., Verdoodt V., Mechelen M.V., Jasmontaite L. Faraway, so close: why the digital industry needs scholars and the other way around // Journal of Children and Media. 2016. Vol. 10 (2). P. 200-207.

Fotel, Thomsen 2004 - Fotel T., Thomsen T. The Surveillance ofChildren's Mobility// Surveillance \& Society. 2004. Vol. 1 (4). P. 535-554. 
Goodchild 2007 - Goodchild M.F. Citizens as sensors: the world of volunteered geography // GeoJournal. 2007. Vol. 69. P. 211-221.

Hochschild 1995 -Hochschild A. The culture of politics: traditional, postmodern, coldmodern, and warmmodern ideals of care // Social Politics. 1995. Vol. 2, № 3. P. 331-346.

Palmer 2006 - Palmer S. Toxic Childhood: How the Modern World is Damaging our Children and what We Can Do about It. L.: Orion, 2006.

Qvortrup 1991 - Qvortrup J. Childhood as a social phenomenon. Budapest: Centre for Social Welfare Policy and Research, 1991.

Rose 2014 - Rose D. Enchanted Objects: Design, Human Desire, and the Internet of Things. N. Y.: Scribner, 2014.

Valentine, Mckendrick 1997 - Valentine G., Mckendrick J. Children's outdoor play: exploring parental concerns about children's safety and the changing nature of childhood // Geoforum. 1997. Vol. 28 (2). P. 219-235.

\section{REFERENCES}

Majofis M.L., Kukulin I.V., 2010. New parenthood and its political aspects. Pro et Contra, vol. 14, no. 1-2, pp. 6-19.

Sveshnikova O., 2010. Russian parents: new in behavior and perception of the world. Pro et Contra, vol. 14, no. 1-2, pp. 61-77.

Shpakovskaya L.L., 2013. Discursive parenting practices: political challenges and current issues. Bulletin of Tomsk State University Philosophy. Sociology. Political science, no. 1 (21), pp. 236-248.

Barker J., 2003. Passengers or Political Actors? Children's Participation in Transport Policy and the Micro Political Geographies of the Family. Space and Polity, vol. 7 (2), pp. 135-151.

Bijker W.E., Hughes T.P., Pinch T.J., 1993. The Social Construction of Technological Systems. New directions in the Sociology and History of Technology. London, The MIT Press Cambridge.

Blinkert B., 2004. Quality of the City for Children: Chaos and Order. Children, Youth and Environments, vol. 14 (2), pp. 99-112.

Donoso V., Verdoodt V., Mechelen M. V., Jasmontaite L., 2016. Faraway, so close: why the digital industry needs scholars and the other way around. Journal of Children and Media, vol. 10 (2), pp. 200-207.

Fotel T., Thomsen T. 2004. The Surveillance of Children's Mobility. Surveillance \& Society, vol. 1 (4), pp. 535-554.

Goodchild M.F., 2007. Citizens as sensors: the world of volunteered geography. GeoJournal, no. 69, pp. 211-221.

Hochschild A., 1995. The culture of politics: traditional, postmodern, coldmodern, and warmmodern ideals of care. Social Politics, vol. 2, no. 3, pp. 331-346.

Palmer S., 2006. Toxic Childhood: How the Modern World is Damaging our Children and what We Can Do about It. London, Orion.

Qvortrup J., 1991. Childhood as a social phenomenon. Budapest, Centre for Social Welfare Policy and Research.

Rose D., 2014. Enchanted Objects: Design, Human Desire, and the Internet of Things. New York, Scribner.

Valentine G., Mckendrick J. 1997. Children's outdoor play: exploring parental concerns about children's safety and the changing nature of childhood. Geoforum, vol. 28 (2), pp. 219-235.

\section{Information About the Author}

Elena G. Laktyukhina, Candidate of Sciences (Sociology), Associate Professor, Department of Sociology, Volgograd State University, Prosp. Universitetsky, 100, 400062 Volgograd, Russian Federation, laktyukhina@volsu.ru,https://orcid.org/0000-0003-4003-3643

\section{Информация об авторе}

Елена Геннадьевна Лактюхина, кандидат социологических наук, доцент кафедры социологии, Волгоградский государственный университет, просп. Университетский, 100, 400062 г. Волгоград, Российская Федерация, laktyukhina@volsu.ru, https://orcid.org/0000-0003-4003-3643 